\title{
The role of psychosocial stress at work for the development of cardiovascular diseases: a systematic review
}

\author{
Eva-Maria Backé • Andreas Seidler • \\ Ute Latza $\cdot$ Karin Rossnagel $\cdot$ Barbara Schumann
}

Received: 21 October 2010/Accepted: 21 April 2011/Published online: 17 May 2011

(c) The Author(s) 2011. This article is published with open access at Springerlink.com

\begin{abstract}
Purpose A systematic review was carried out to assess evidence for the association between different models of stress at work, and cardiovascular morbidity and mortality. Methods A literature search was conducted using five databases (MEDLINE, Cochrane Library, EMBASE, PSYNDEX and PsycINFO). Inclusion criteria for studies were the following: self-reported stress for individual workplaces, prospective study design and incident disease (myocardial infarction, stroke, angina pectoris, high blood pressure). Evaluation, according to the criteria of the Scottish Intercollegiate Guidelines Network, was done by two readers. In case of disagreement, a third reader was involved.

Results Twenty-six publications were included, describing 40 analyses out of 20 cohorts. The risk estimates for work stress were associated with a statistically significant increased risk of cardiovascular disease in 13 out of the 20 cohorts. Associations were significant for 7 out of 13
\end{abstract}

E.-M. Backé $(\bowtie) \cdot$ A. Seidler · U. Latza · K. Rossnagel ·

B. Schumann

Federal Institute for Occupational Safety and Health,

Nöldnerstraße 40-42, 10317 Berlin, Germany

e-mail: Backe.eva-maria@baua.bund.de

Present Address:

A. Seidler

Institute and Policlinic of Occupational and Social Medicine

(IPAS), Technical University Dresden,

Fetscherstraße 74, 01307 Dresden, Germany

Present Address:

B. Schumann

Department of Public Health and Clinical Medicine,

Epidemiology and Global Health, Umeå University,

90187 Umeå, Sweden cohorts applying the demand-control model, all three cohorts using the effort-reward model and 3 out of 6 cohorts investigating other models. Most significant results came from analyses considering only men. Results for the association between job stress and cardiovascular diseases in women were not clear. Associations were weaker in participants above the age of 55 .

Conclusions In accordance with other systematic reviews, this review stresses the importance of psychosocial factors at work in the aetiology of cardiovascular diseases. Besides individual measures to manage stress and to cope with demanding work situations, organisational changes at the workplace need to be considered to find options to reduce occupational risk factors for cardiovascular diseases.

Keywords Psychosocial stress at work - Job strain . Demand-control model - Effort-reward imbalance model . Cardiovascular diseases $\cdot$ Systematic review

\section{Introduction}

Cardiovascular diseases (CVD) are the major cause of death and morbidity in Western countries, accounting for more than half of all deaths (American Heart Association 2005). Despite declining mortality of chronic heart disease in the last decade, the incidence and prevalence of chronic heart disease are still high (Mosterd et al. 1998; Raymond et al. 2003; Roger et al. 2004). Thus, cardiovascular disease remains a serious public health problem and an economic burden for society and its health care system (O'Connell 2000; Stewart et al. 2003).

The relationship between adverse working conditions and CVD has been investigated for many decades, including studies on the effect of physical workload, noise, 
long working hours, shift work and social job characteristics such as occupational position. Special attention has been given to the role of work stress. The mechanisms underlying the association between work stress and heart disease remain still unclear. Possible pathways are through the direct activation of neuroendocrine responses to stressors or more indirectly through unhealthy behaviours, such as smoking, lack of physical exercise or excessive alcohol consumption (Chandola et al. 2008).

Since the mid-1990s, more sophisticated studies on psychosocial stress at work based on theoretical models of stress have emerged. Two theoretical models on work stress were developed, and with them, validated and standardised methods assessing work stress were introduced into epidemiological research.

The demand-control or job strain model by Karasek et al. (1998) is the most often used stress model. It is based on the assumption that a mismatch between low control over working conditions (decision latitude) and high demand in terms of work load is particularly hazardous to health, while high control and low demand are the most beneficial. By cross-tabulating the scales of job demand and decision latitude, both divided at their median, four categories, or quadrants, are obtained: active jobs (high demands, high control), passive jobs (low demands, low control), high strain (high demands, low control) and low strain (low demands, high control).

With growing research evidence, the model has been expanded by the inclusion of social support into the socalled isostrain model, posing that a combination of low control, high demand and lack of social support at the workplace has the highest health risk.

Another well-known theoretical approach is the effortreward imbalance (ERI) model by Siegrist (1996a, b) that focuses on the lack of reciprocity as a source of stress at the workplace. According to this model, rewards such as money, esteem and career opportunities will buffer the negative effect of efforts spent in terms of psychological and physical load. An imbalance, on the other hand, will lead to stress and hence to ill health. The ratio of the respective scores of effort and reward constitutes the measure of stress; a ratio above 1 indicates the presence of an imbalance between effort and reward. An extension of the ERI model takes overcommitment into account (Siegrist et al. 2004). This refers to a motivational pattern of excessive work-related commitment and high need for approval. Overcommitment is a psychological risk factor in itself that adds to the strain of working conditions. Besides these theory-based approaches to assess stress at work, a large number of studies based on questionnaires of stressrelated items dealing with long working hours, time pressure, interpersonal conflicts and other psychosocial aspects of work have been conducted (e.g. Theorell and Floderus-
Myrhed 1977; Suadicani et al. 1993; Hibbard and Pope 1993; Matthews and Gump 2002).

While cross-sectional, case-control and prognostic studies still dominate in the literature, a large number of well-designed prospective cohort studies have been conducted in the last years. These contribute a higher degree of evidence to the causal relationship between work stress and health.

Numerous reviews have been published on the relation between stress and CVD (e.g. Costa 2004; Dimsdale 2008; Karasek 2006). Unfortunately, most of the reviews are narrative in nature and thus not transparent and not as comprehensive. Eller et al. (2009), Kivimäki et al. (2006), Netterstrøm and Kristensen (2005), Belkic et al. (2004) and Hemingway and Marmot (1999) conducted systematic reviews. These employ an explicit research strategy with predefined search terms for identifying every publication in the field and analyse the results in a systematic, objective manner in order to minimise bias. Usually, the quality of each study in respect to its level of evidence of results is taken into account, giving more weight to higher-level studies with less risk of bias or confounding (such as randomised trials or cohort studies) than to studies with methodological restrictions.

The aim of the present study was to conduct an up-todate systematic review based on longitudinal data on the association of psychosocial stress at work with cardiovascular diseases. A broader definition of work stress and cardiovascular outcomes was applied.

The following questions were assessed:

- Is stress at work related to cardiovascular morbidity and mortality (coronary heart disease, stroke and hypertension)?

- Which stress models and which CVD outcomes have the strongest evidence for an association?

\section{Methods}

The authors performed a systematic review on the role of work stress for the development of cardiovascular diseases by collecting and analysing all relevant publications with a predefined strategy. The authors intended to include a variety of databases besides MEDLINE, possibly identifying articles published in less-known journals and older publications, and to include those based on less-known stress models.

All studies dealing with stress perceived at work (search terms: psychosocial stress at work, work stress, occupational stress, mental stress, job strain, effort, reward, demand, control with cardiovascular diseases and hypertension) were included. Self-reported and expert-rated 
assessment for individual workplaces was taken into account, while those articles based on job titles were excluded. Studies dealing exclusively with organisational factors (e.g. overtime work) were also excluded.

Inclusion criteria of diseases were cardiovascular disease, coronary heart disease, myocardial infarction, heart failure, angina pectoris, stroke and hypertension. Outcomes such as atherosclerosis, blood pressure described as a metric variable and other subclinical measures as well as gestational hypertension were not included in this review.

In order to minimise bias from reversed causality as well as recall bias and other methodological restrictions, only prospective aetiological cohort studies and randomised controlled trials (RCT) were included. Prognostic studies with CVD patients were excluded from the analyses. In addition, case-control, cross-sectional and aggregated studies, as well as narrative reviews were excluded. Further, systematic reviews were checked for studies that had been missed by the search strategy of the presented systematic review. Relevant publications were added to the analyses.

Scientific articles were identified from MEDLINE, EMBASE, PSYNDEX, PsycINFO and Cochrane Library with defined search terms (see above). A senior medical information specialist performed the search in July 2008. After finishing the main data analyses, the procedure was repeated in March 2010 to identify studies published since the first search (see Fig. 1).

Two readers (EM.B and B.S.) decided independently on inclusion or exclusion of all identified publications based on title and-if available - abstract. In order to avoid bias, readers were blinded to the name of the authors. In case of disagreement, consent was achieved by discussion, or a third reader (A.S.) was involved.

Multiple publications based on the same cohort were retained if they involved analyses on different exposure methods or outcomes, e.g. stress measured as job strain and as effort-reward imbalance. If outcomes differed only slightly, such as cardiovascular morbidity and mortality, the most comprehensive publication was considered. If exposure, methods and outcomes were identical in two articles, they were regarded as multiple publications and the one which was described in more detail was retained.

Retrieved papers were evaluated by the two readers in respect to the level of evidence using a modified version of the Scottish Intercollegiate Guidelines Network (SIGN) checklist for cohort studies (Scottish Intercollegiate Guidelines Network 2008; Harbour and Miller 2001). Since no randomised trials were found, the respective SIGN checklist for RCTs was not applicable. A third reader (A.S.) served as an arbiter in case of disagreement concerning the level of evidence of a study.

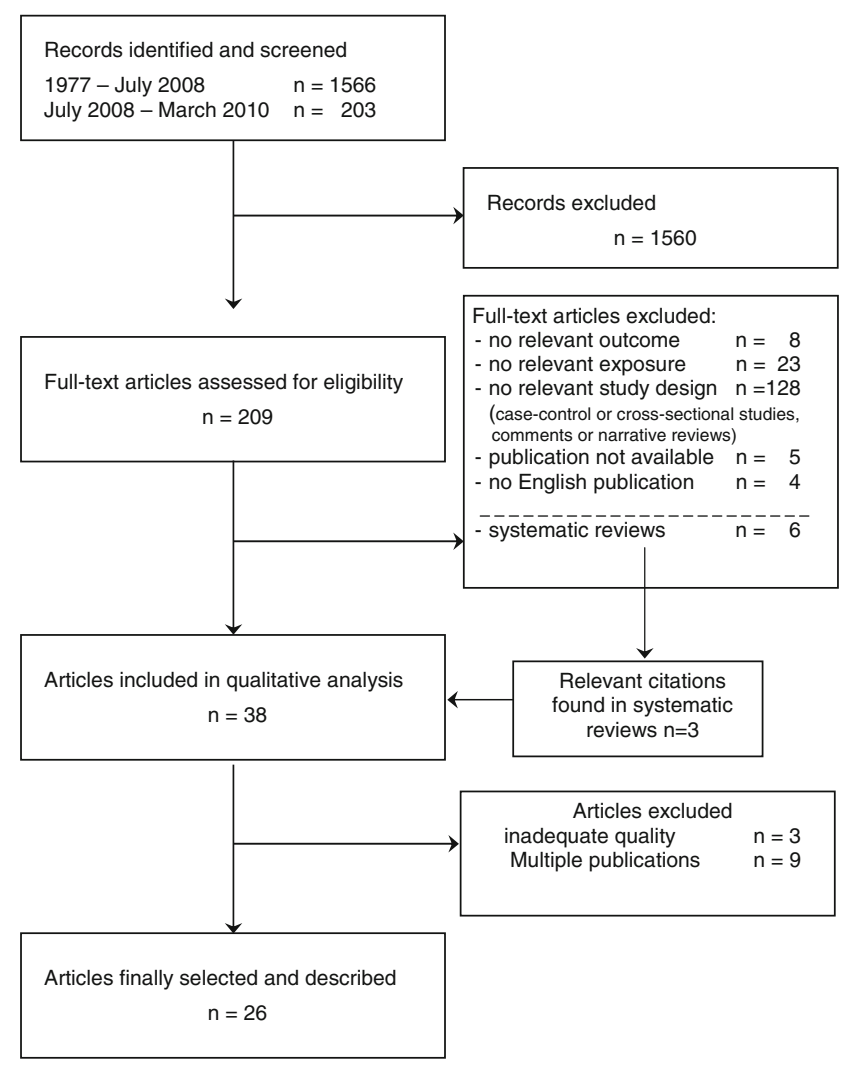

Fig. 1 Flowchart

The SIGN checklists were applied to grade the level of evidence of each study.

Overview of included studies

The search yielded 1,769 citations for the period between 1977 and March 2010, of which 26 were finally selected according to the inclusion criteria. All studies were cohort studies; no randomised controlled trials covering this topic were found. All studies included were in English. For details of the literature search, see Fig. 1 (flowchart). Twenty cohorts were described in the selected 26 publications. Some of these 26 publications included more than one exposure model, or more than one outcome, or results were gender-stratified. Thus, 40 different analyses were described (see Tables 1, 2, 3) and considered within the following systematic evaluation.

In the majority of the cohorts, participants were recruited from an unselected general working population. The remaining studies included selected occupations or companies (see Tables 1, 2, 3 for details).

Nine cohorts investigated only men and three cohorts only women. Twelve publications (eight cohorts) described both men and women. Ten of the 15 analyses examining only male participants yielded significant positive results, 


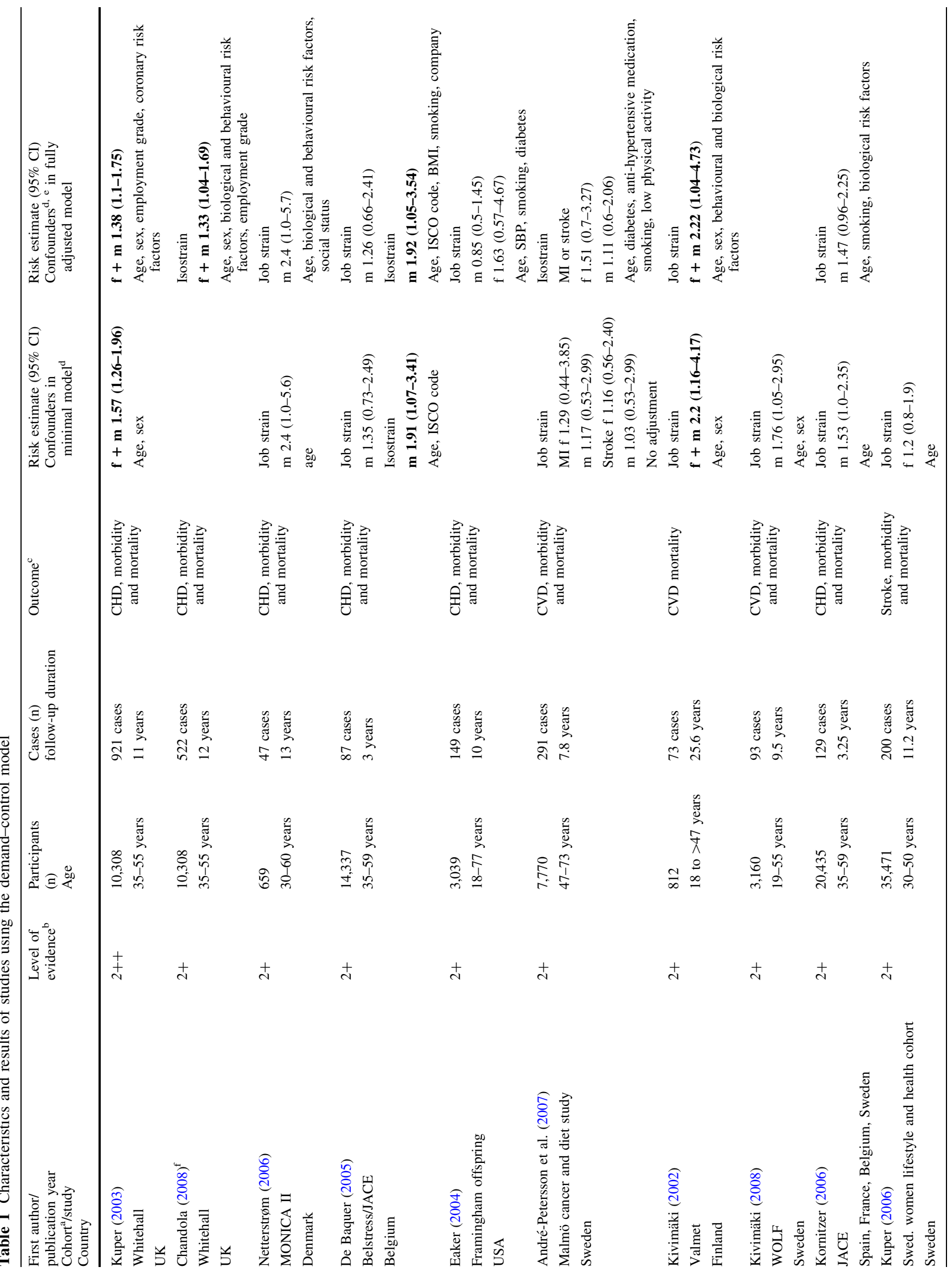




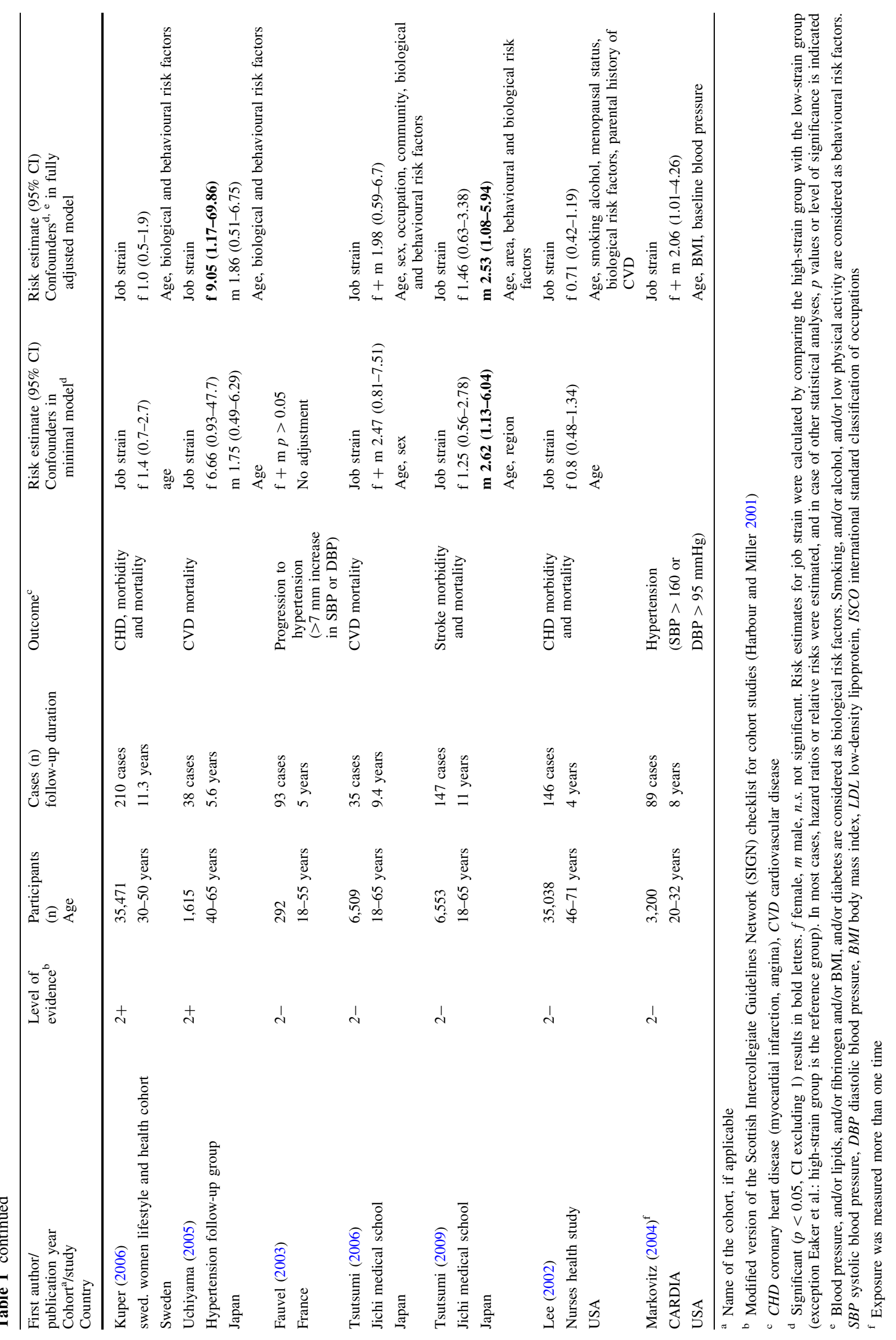




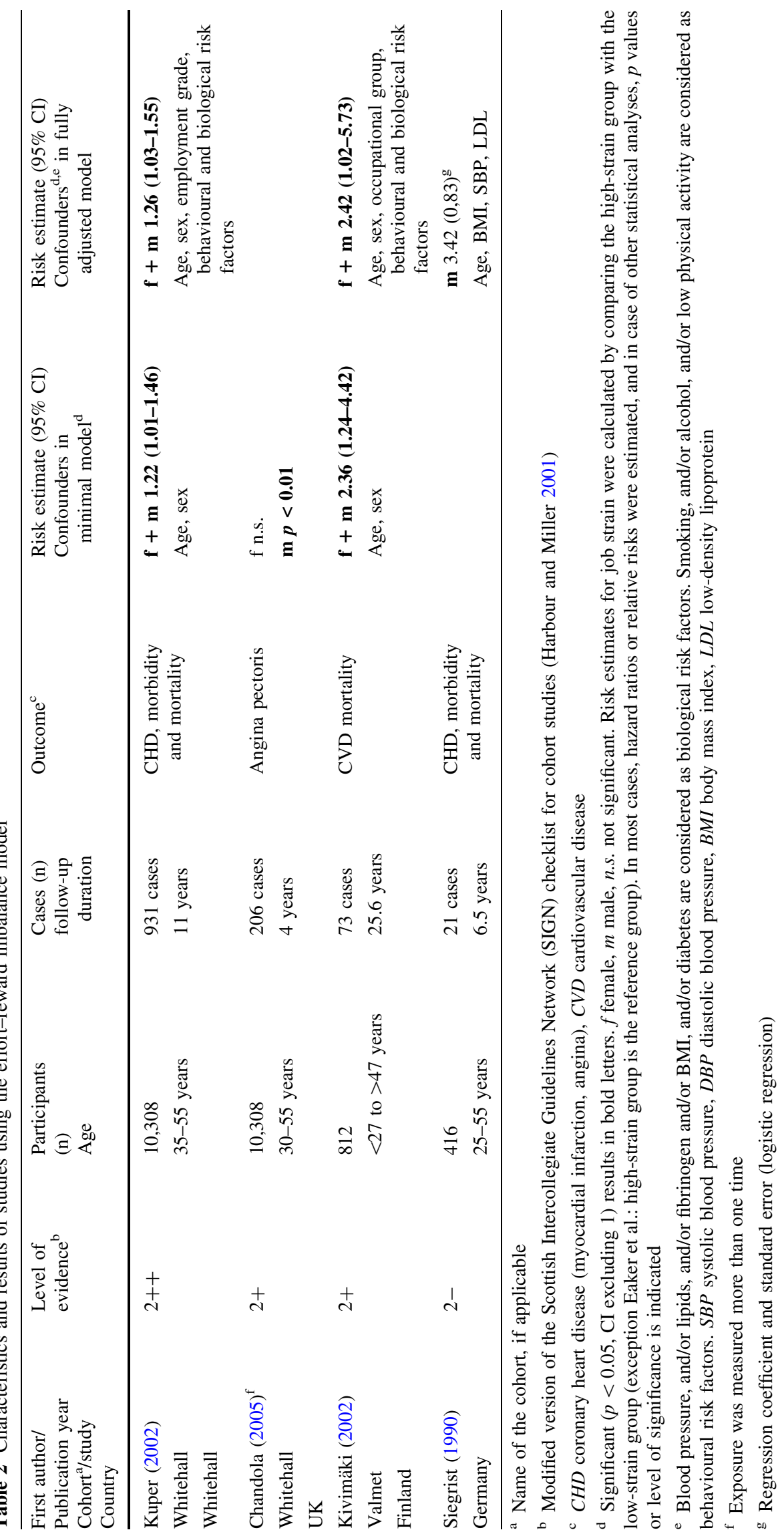




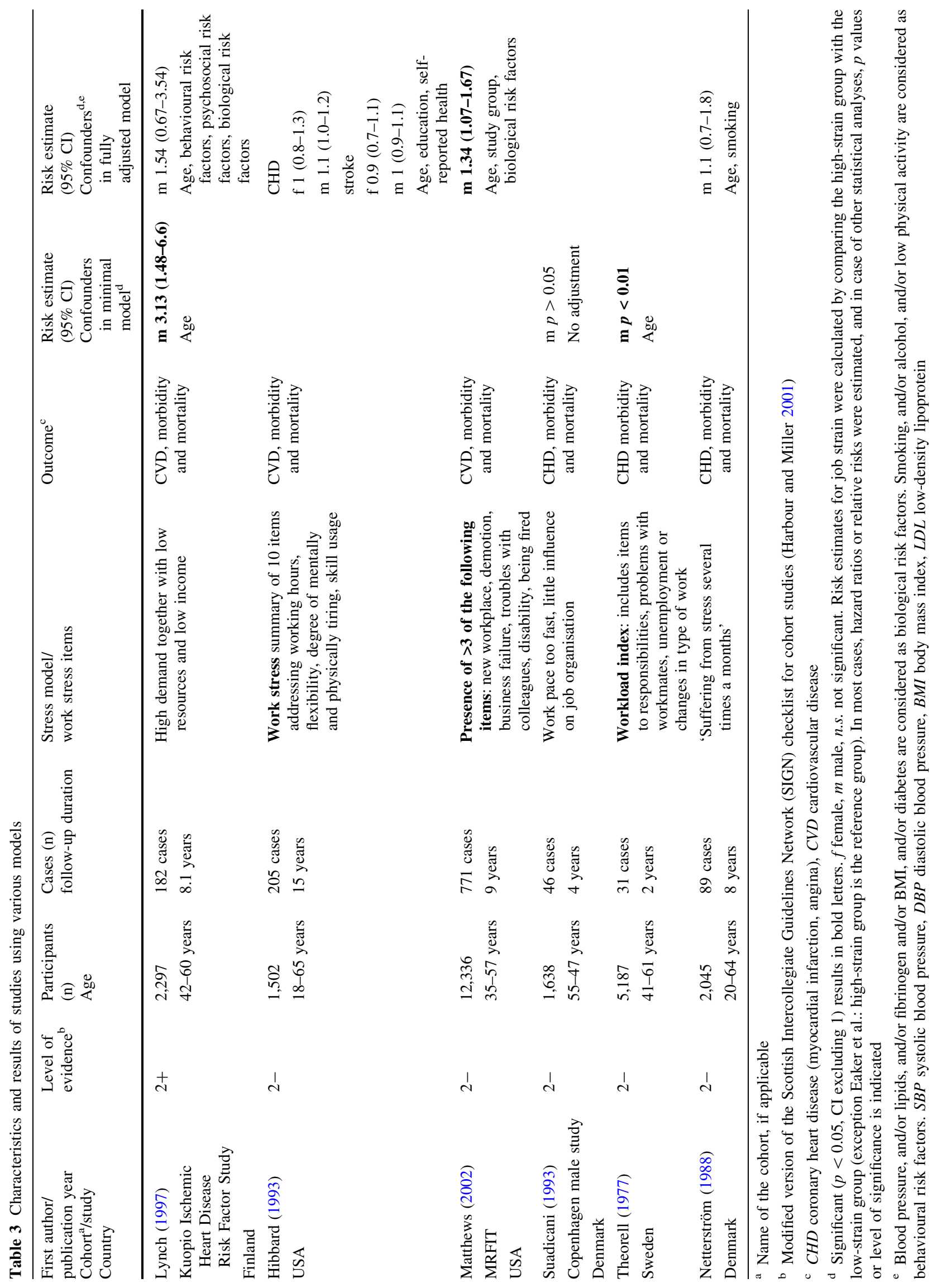


whereas only one of the nine analyses observing exclusively women showed significant positive results.

In summary, statistically significant associations between psychosocial stress and cardiovascular disease were described in 14 out of 26 publications ( 11 out of 20 cohorts, respectively). With the exception of the Nurses Health Study (Lee et al. 2002), all studies that reported risk estimates indicated a higher risk of cardiovascular diseases with increasing stress. However, not all of these results were statistically significant. Most of the significant results came from studies including only men; thus, no clear statement is possible for the association between job stress and cardiovascular diseases in women.

The majority of the investigations described either overall cardiovascular disease or coronary heart disease, either based on mortality registers or (for morbidity) collected by questionnaires, clinical diagnosis based on ECG or enzyme measurement. Some analyses regarded solely stroke (Tsutsumi et al. 2009; André-Petersson et al. 2007; Kuper et al. 2006; Hibbard and Pope 1993), angina pectoris (Chandola et al. 2005) or hypertension (Fauvel et al. 2003; Markovitz et al. 2004). Since most of the studies investigated cardiovascular disease or heart disease as a whole, it was not possible to evaluate whether work stress acts differently in relation to myocardial infarction, angina pectoris, hypertension or stroke within the same study population. Results were significant for six out of 14 publications investigating CHD, and for five out of seven articles on CVD. One of the two publications on hypertension, one of the two publications on stroke and one publication on angina pectoris revealed statistically significant positive associations.

The two publications with the highest level of evidence (SIGN classification $2++$, indicating a study with highquality and a very low risk of confounding and bias) for the relationship between stress and cardiovascular disease were based on the Whitehall cohort. One publication (Kuper et al. 2003) used the job strain model and the other one (Kuper et al. 2002) the effort-reward imbalance model to describe stress at the workplace (Tables 1,2). Both found statistically significant results. Thirteen publications showed a low risk of bias and a moderate probability that the relationship investigated was causal (SIGN classification 2+), eight of these 13 studies described significant results. The remaining eleven publications had a high risk of confounding and bias (SIGN classification 2-). Statistical analysis and adjustment for potentially confounding factors were insufficient in some of these studies.

\section{Demand-control model}

Seventeen publications used the job strain model to describe stress at the workplace (Table 1). In seven of the
13 cohorts, workers with high strain had a significantly higher risk to develop cardiovascular diseases than workers in the low-strain group. Risk estimates varied between 1.33 and 2.62. Markovitz et al. (2004) reported a significant association between changes in job strain (of increasing demands relative to decreasing decision latitude) and risk of hypertension. A cumulative index was used in one study (Chandola et al. 2008), and the results indicate a doseresponse relationship between the frequency of stress and cardiovascular outcomes.

In three publications, also 'isostrain', a combination of high job strain and lack of social support at work, was investigated (André-Petersson et al. 2007; De Bacquer et al. 2005; Chandola et al. 2008). Two investigations found significant associations between isostrain and cardiovascular disease (De Bacquer et al. 2005; Chandola et al. 2008). Age-stratified analyses in two articles (Kivimäki et al. 2008; Chandola et al. 2008) indicated that the association between job strain and cardiovascular diseases is not as strong in participants older than 55 years.

\section{Effort-reward imbalance model}

Three cohorts, described in four publications, applied the effort-reward imbalance model (Table 2). Statistically significant associations were found in all these investigations. In the Valmet study (Kivimäki et al. 2002), a more than twofold risk, and in the Whitehall study (Kuper et al. 2002), a 1.2-fold risk to develop coronary heart disease (CHD) were estimated. Within the Whitehall study, temporal changes in exposure (increase in ERI score between phase 1 and phase 5) in men were statistically significant related to the development of angina pectoris (Chandola et al. 2005).

\section{Other models}

Three of the six cohorts that applied other exposure measurements than the demand-control or effort-reward imbalance model suggested an elevated risk of cardiovascular disease following psychosocial stress (Table 3). One model that is comparable to the effort-reward imbalance model (Lynch et al. 1997) showed significant results, and the other two cohorts with significant results used indices consisting of several items related to stress.

\section{Discussion}

This systematic review describes 26 articles investigating 20 study cohorts. The discussion of the results is based upon 40 different analyses. The included studies were diverse regarding the investigation into and description of 
exposure to psychosocial load. Psychosocial factors acting as stressors in daily work are multifaceted, and each exposure model addresses different aspects of a work situation. Besides the aspects addressed in the exposure models described in these 26 publications, there may be also other stressors, e.g. bullying at work or ambiguity concerning work tasks, but also external factors like noise leading to amplified experience of stress and demands.

Presently, there is no agreement (Eller et al. 2009; Bosma et al. 1998; Belkic et al. 2004) whether the two scales of high demands or low control observed separately have stronger effects on cardiovascular health than the concept of 'job strain' that is based on both scales, demand and control. The authors excluded studies from this review that investigated only one scale of the stress models since the traditional concept of 'job strain' is based on both scales, demand and control.

Work stress might also have an impact on re-events after myocardial infarction or on the prognosis of other cardiovascular diseases. Such prognostic studies, however, were excluded from the analyses. Since most of the studies have not been specifically designed to answer the question whether there is an association between work stress and cardiovascular disease, detailed job descriptions were not available in most of the investigations. Outcomes, statistical models and confounders such as biological and behavioural risk factors were also heterogeneous. Thus, a meta-analysis was not conducted.

\section{Findings}

The presented systematic review affirms the first research question, since the collected studies revealed moderate evidence that stress at work is related to cardiovascular morbidity and mortality. The strength of association depended on the stress model employed and the population or subgroups examined. All studies based on the effortreward imbalance model, and about half of the studies with the job strain model revealed an impact of work stress on cardiovascular disease. So far, the ERI model seems to be a more consistent predictor of cardiovascular diseases. However, the ERI approach was used in only three studies. Thus, the answer to the question which stress model has the strongest evidence for an association with cardiovascular diseases is not unambiguous.

With one exception (Lee et al. 2002), all risk estimates showed a positive association between psychosocial stress at the workplace and cardiovascular disease. However, statistically significant results were described for only 13 out of the 20 cohorts investigated (Tables 1,2,3). Some issues may explain the non-significant results.

Most of the included studies assessed job strain at one point in time only. Three analyses (Chandola et al. 2005,
2008; Markovitz et al. 2004) that measured either temporal changes in job stress or cumulative stress reported statistically significant associations with disease. However, more studies with sophisticated assessment of the development of job stress over time and its impact on health are desirable. Another aspect is the long follow-up duration in some of the studies. As a consequence, information bias might be introduced unless job strain is stable for a long time and workers do not change and leave their job or experience times of unemployment. Job change due to stress will underestimate the effect, in case vulnerable individuals may have already left work. In the Whitehall study, the effect of effort-reward imbalance on cardiovascular health indicated higher risk estimates after an average follow-up time of 5.3 years (Bosma et al. 1998) than after a follow-up time of 11 years (Kuper et al. 2002). However, the outcome in the two analyses differed. Bosma et al. (1998) considered cardiovascular morbidity and mortality and Kuper et al. (2002) only cardiovascular morbidity. The possible conclusion of an underestimation of true effect estimates in long-term studies needs further investigations.

In some studies included in our review, only few events occurred. Thus, the statistical power was probably not strong enough to observe significant results (e.g. Tsutsumi et al. 2006).

\section{Demand-control model}

Self-reported job demands might be difficult to measure across different occupational groups because they may experience and interpret job demands in a different way. However, this is contradicted by two studies investigating only one occupational group (bus drivers, nurses) that show no significant results. The study investigating nurses (Lee et al. 2002) even described risk estimates below 1. On the other hand, a rather similar degree of job stress within one occupational group can be discussed as an explanation for a missing association. Comparability of the results of the different studies is also restricted because of different versions of the Job Content Questionnaire (JCQ) and different allocation into the four different groups (high strain, low strain, active job and passive job) according to the demand-control model.

\section{Effort-reward imbalance model}

Results were more consistent for the concept of effortreward imbalance than for the job strain model. The results of all three cohorts yielded significant results suggesting the concept of effort-reward imbalance as a predictor for cardiovascular diseases. Results of the Whitehall study have already been discussed in an earlier publication (Bosma et al. 1998, publication not included in the tables). 
The authors describe even higher risk estimates than Kuper et al. (2002). Yet, the observed outcome was cardiovascular morbidity, not mortality as in the publication of Kuper et al. Since the effort-reward model was used in only three cohorts, results are limited and need to be confirmed. In addition, different versions of the effortreward imbalance questionnaire were used in these studies that may limit comparability.

\section{Other models}

The six cohorts investigating exposure models that are not as validated and standardised as the effort-reward imbalance model or the job strain model all use different instruments. Thus, results are not comparable. Additionally, the quality of many of these studies was low. One exception was the Kuopio Ischemic Heart Disease Risk Factor Study (Lynch et al. 1997), describing an exposure model (demand/resources/income) that is quite similar to the effort-reward imbalance model. This study adds to the positive results found by the studies using the ERI concept. Results of the Multiple Risk Factor Intervention Trial (MRFIT) (Matthews and Gump 2002) and the results of the study by Theorell and Floderus-Myrhed (1977) show that even an exposure measure including a sum score of questions concerning work stress such as changes in job, problems with workmates or getting unemployed is related to cardiovascular outcomes.

\section{Gender and age effects}

There appear to be gender differences for the influence of work stress on cardiovascular disease. In the Nurses Health Study that enrolled a high number of female nurses' risk estimates were below 1, indicating an inverse (although non-significant) relationship. The Swedish Woman Lifestyle Study found positive associations although not reaching significance. Chandola et al. (2005) described a significant relation between the change in effort-reward imbalance and angina pectoris in men, but not in woman. A study by Tsutsumi et al. (2006) investigating the relationship between job stress and stroke indicated a risk estimate of 1.25 for women (not significant) and a risk estimate of 2.6 for men.

Several reasons may explain differences between the results found for men and women. First, cardiovascular events in women occur later in life than in men; thus, the investigated cohorts, including mainly working populations, might have been too young to observe cardiovascular events. Additionally, in most of the studies, no information was available concerning psychosocial burden or resources at home that may have an even stronger impact on women's health, as shown by Orth-Gomer et al. (2000).
There was also sparse information concerning part-time work that is probably more frequent in the female population. As shown for the association between job strain and depression (Ertel et al. 2008), social support as well as family demands may moderate the effect of job strain on cardiovascular health in women. There may be also gender differences in the experience of stress (de Smet et al. 2005) leading to differing answers to the questionnaire. Another reason for inconsistent results in the included studies may be the inclusion of participants of different age. High age seems to dilute the association between job stress and disease (Kivimäki et al. 2008). This may be due to a healthy worker effect or due to adjustment to stressful working conditions. Additionally, lower risk due to psychosocial stress at work in higher age may be due to concurring classical risk factors, e.g. high blood pressure that become relatively more important with increasing age.

\section{Other cardiovascular risk factors}

With only one exception, all studies describing risk estimates that were included in this review showed positive associations between work stress and cardiovascular outcomes, although not all of them reached statistical significance. Of those publications including several statistical models $(n=16)$, the multiple adjustment leads to a lower risk estimate in $50 \%$ ( 8 out of 16 models); in few analyses (5 out of 16 models), a higher risk estimate was observed or the risk estimate remained unchanged ( 3 out of 16 models). Nevertheless, adjustment to biological and behavioural factors did not explain completely the associations found between work stress and cardiovascular events. Since CHD takes decades to develop and is associated with a large variety of risk factors in childhood and adulthood, there may be some other unidentified important confounding factors, already present before being employed (Kivimäki et al. 2006). However, new results from the Whitehall study (Hintsa et al. 2010) indicate that the association between psychosocial factors at work and CHD is largely independent of family history of CHD, education, paternal educational attainment social class, number of siblings and height.

\section{Previous reviews}

This review continues and adds to other previous systematic reviews (Eller et al. 2009; Kivimäki et al. 2006; Netterstrøm and Kristensen 2005; Belkic et al. 2004; Hemingway and Marmot 1999). Unique in the presented review is the inclusion of additional databases beside MEDLINE. This approach retrieved additional publications that did not appear in the other systematic reviews (Chandola et al. 2005, 2008; Fauvel et al. 2003; Hibbard 
and Pope 1993; Markovitz et al. 2004; Matthews and Gump 2002; Tsutsumi et al. 2006, 2009). The authors restricted the selection to prospective cohort studies and randomised trials (none of the latter was identified in the literature search) in order to avoid selection bias and recall bias particularly present in case-control studies. Most of the existing reviews focus on the job strain and the effortreward imbalance models, whereas the presented review included several studies based on less-known approaches. These latter studies tended to be less sophisticated and lacked a theoretical foundation. However, this finding could not be anticipated beforehand.

Furthermore, hypertension besides myocardial infarction and stroke was included. Thus, some studies and/or analyses that have not been considered in the previous reviews were included here. Chandola et al. (2005, 2008) analysed data of the Whitehall cohort taking into account exposure measurements at two points in time, and both analyses support the association of stress and cardiovascular disease. Hibbard and Pope (1993) as well as Matthews and Gump (2002) used exposure models depending on sum scores of different items. Results of the MRFIT study (Matthews and Gump 2002) indicate that job stress is a risk factor for cardiovascular disease. Data from the Jichi Medical cohort (Tsutsumi et al. 2006, 2009) indicate a significant association between job strain and stroke in men. Of the two studies investigating hypertension (Fauvel et al. 2003; Markovitz et al. 2004), the study by Markovitz et al. (2004) found significant results. Even with these additional data, the presented findings are in agreement with the previous systematic reviews or meta-analyses confirming the association between job stress and cardiovascular disease especially in men.

All reviews support the European guidelines for the prevention of cardiovascular diseases in clinical practice (Orth-Gomer et al. 2005) that name the importance of work stress-related questions when counselling patients with cardiovascular risk.

Future research

Since work life is changing continuously, the relative importance of a single stress factor will also change. New types of stressors are emerging and need to be considered in exposure models describing psychosocial burden. A recent prospective study (Virtanen et al. 2010) describes the association of overtime work and incident coronary heart disease. More detailed models requesting different issues related to the experience of stress (e.g. leadership, conflicts, clarity concerning work task, job insecurity) at the workplace need to be included in future study designs.

Future studies should include multiple measurement of work stress to monitor temporal changes. Additionally, questions concerning psychosocial burden at home and information about work-privacy conflict that seems to be especially important in the female participants need to be enclosed (Orth-Gomer et al. 2005).

With the inclusion of other work-related factors in the study design such as noise, physical workload and shift work as well as the enquiry of several lifestyle factors, interactions between risk factors can be analysed, given adequate statistical power. This will permit new concepts concerning the multifactorial aetiology of cardiovascular diseases and their prevention. Data need to be stratified for potential effect modifiers such as age groups and gender. There is a clear need for primary interventions examining the effects of lowering work stress by enhancing the ability of coping as well as changes in work organisation (e.g. changes related to demands, decision authority, quality of leadership). Events enhancing stress such as organisational downsizing have already shown to increase the risk of cardiovascular death (Vahtera et al. 2004). Also, individual risk profiles, such as cardiovascular reactivity or inflammatory response following an acute stress situation, need to be investigated and considered, since the same challenges may not induce similar stress responses in all workers. A recent meta-analysis (Chida and Steptoe 2010) showed that a higher cardiovascular response to laboratory mental stress is related to poor cardiovascular status. Also, stressinduced inflammatory responses may have implications for future health (Steptoe et al. 2007). Success of interventions needs to be monitored by measuring subclinical changes rather than long-term outcomes such as cardiovascular mortality. Candidates for subclinical parameters were discussed in a recent review about the effect of psychosocial working environment on physiological changes in blood and urine (Hansen et al. 2009). Carotid intima media thickness ( $\mathrm{Tu}$ et al. 2010) and arterial stiffness (Utsugi et al. 2009) are parameters that seem to be increased following high job strain or effort-reward imbalance.

\section{Summary}

In line with other systematic reviews, this publication provides moderate evidence that psychosocial factors at work are related to cardiovascular diseases. However, none of the stress models used in epidemiological research has so far proven to satisfactorily elucidate the stress-disease relationship. Both the job strain and the effort-reward imbalance model are promising despite the limitation of existing studies. It is not yet clear whether individual factors (e.g. coping, overcommitment) or the objective working conditions (e.g. time pressure, work organisation), which both contribute to the individual perception of work stress, have a stronger impact. Apart from individual measures to manage stress and to cope with demanding 
work situations, organisational changes at the workplace need to be considered to find options to reduce occupational risk factors for cardiovascular diseases.

Acknowledgments We thank Dr. Gabriele Menzel of the Charite library Berlin, for her support with the literature search in five databases and Sylvia Behrendt for the assistance with the literature management.

Conflicts of interest The authors declare that they have no conflict of interest.

Open Access This article is distributed under the terms of the Creative Commons Attribution Noncommercial License which permits any noncommercial use, distribution, and reproduction in any medium, provided the original author(s) and source are credited.

\section{References}

American Heart Association (2005) Heart disease and stroke statistics-Update 2005. http://www.americanheart.org/download able/heart/1105390918119HDSStats2005Update.pdf. Accessed 01 Sept 2010

André-Petersson L, Engstrom G, Hedblad B (2007) Social support at work and the risk of myocardial infarction and stroke in women and men. Soc Sci Med 64:830-841

Belkic KL, Landsbergis PA, Schnall PL, Baker D (2004) Is job strain a major source of cardiovascular disease risk? Scand J Work Environ Health 30:85-128

Bosma H, Peter R, Siegrist J, Marmot M (1998) Two alternative job stress models and the risk of coronary heart disease. Am J Public Health 88(1):68-74

Chandola T, Siegrist J, Marmot M (2005) Do changes in effort-reward imbalance at work contribute to an explanation of the social gradient in angina? Occup Environ Med 62:223-230

Chandola T, Britton A, Brunner E, Hemingway H, Malik M, Kumari M, Badrick E, Kivimäki M, Marmot M (2008) Work stress and coronary heart disease: what are the mechanisms? Eur Heart J 29:640-648

Chida Y, Steptoe A (2010) Greater cardiovascular responses to laboratory mental stress are associated with poor subsequent cardiovascular risk status: a meta-analysis of prospective evidence. Hypertension 55:1026-1032

Costa G (2004) Cardiopathy and stress inducing factors. Med Lav 95(2):133-139

De Bacquer D, Pelfrene E, Clays E, Mak R, Moreau M, de Smet P, Kornitzer M, De Backer G (2005) Perceived job stress and incidence of coronary events: 3-year follow-up of the Belgian job stress project cohort. Am J Epidemiol 161:434-441

De Smet P, Sans S, Dramaix M, Boulenguez C, de Backer G, Ferrario M, Cesana G, Houtman I, Isacsson SO, Kittel F, Ostergren PO, Peres I, Pelfrene E, Romon M, Rosengren A, Wilhelmsen L, Kornitzer M (2005) Gender and regional differences in perceived job stress across Europe. Eur J Public Health 15(5):536-545

Dimsdale JE (2008) Psychological stress and cardiovascular disease. J Am Coll Cardiol 51:1237-1246

Eaker ED, Sullivan LM, Kelly-Hayes M, D'Agostino RB Sr, Benjamin EJ (2004) Does job strain increase the risk for coronary heart disease or death in men and women? The Framingham offspring study. Am J Epidemiol 159:950-958

Eller NH, Netterstrøm B, Gyntelberg F, Kristensen TS, Nielsen F, Steptoe A, Theorell T (2009) Work-related psychosocial factors and the development of ischemic heart disease: a systematic review. Cardiol Rev 17(2):83-97

Ertel KA, Koenen KC, Berkman LF (2008) Incorporating home demands into models of job strain: findings from the work, family, and health network. J Occup Environ Med 50(11):1244 1252

Fauvel JP, M'Pio I, Quelin P, Rigaud JP, Laville M, Ducher M (2003) Neither perceived job stress nor individual cardiovascular reactivity predict high blood pressure. Hypertension 42:11121116

Hansen AM, Larsen AD, Rugulies R, Garde AH, Knudsen LE (2009) A review of the effect of the psychosocial working environment on physiological changes in blood and urine. Basic Clin Pharmacol Toxicol 105:73-83

Harbour R, Miller J (2001) A new system for grading recommendations in evidence based guidelines. BMJ 323(7308):334-336

Hemingway H, Marmot M (1999) Clinical Evidence: Psychosocial factors in the etiology and prognosis of coronary heart disease: systematic review of prospective cohort studies. West J Med 171(5-6):342-350

Hibbard JH, Pope CR (1993) The quality of social roles as predictors of morbidity and mortality. Soc Sci Med 36:217-225

Hintsa T, Shipley MJ, Gimeno D, Elovainio M, Chandola T, Jokela M, Keltikangas-Järvinen L, Vahtera J, Marmot MG, Kivimäki M (2010) Do pre-employment influences explain the association between psychosocial factors at work and coronary heart disease? The Whitehall II study. Occup Environ Med 67:330-334

Karasek R (2006) The stress-disequilibrium theory: chronic disease development, low social control, and physiological de-regulation. Med Lav 97:258-271

Karasek R, Brisson C, Kawakami N, Houtman I, Bongers P, Amick B (1998) The job content questionnaire (JCQ): an instrument for internationally comparative assessments of psychosocial job characteristics. J Occup Health Psychol 3(4):322-355

Kivimäki M, Leino-Arjas P, Luukkonen R, Riihimäki H, Vahtera J, Kirjonen J (2002) Work stress and risk of cardiovascular mortality: prospective cohort study of industrial employees. BMJ 325:857

Kivimäki M, Virtanen M, Elovainio M, Kouvonen A, Väänänen A, Vahtera J (2006) Work stress in the etiology of coronary heart disease-a meta-analysis. Scand J Work Environ Health 32:431442

Kivimäki M, Theorell T, Westerlund $\mathrm{H}$, Vahtera J, Alfredsson L (2008) Job strain and ischaemic disease: does the inclusion of older employees in the cohort dilute the association? The WOLF Stockholm study. J Epidemiol Commun Health 62(4):372-374

Kornitzer M, deSmet P, Sans S, Dramaix M, Bouleguez C, DeBacker G, Ferrario M, Houtman I, Isacsson SO, Ostergren PO, Peres I, Pelfrene E, Romon M, Rosengren A, Cesana G, Wilhelmsen L (2006) Job stress and major coronary events: results from the job stress, absenteeism and coronary heart disease in Europe study. Eur J Cardiovasc Prev Rehabil 13:695-704

Kuper H, Singh-Manoux A, Siegrist J, Marmot M (2002) When reciprocity fails: effort-reward imbalance in relation to coronary heart disease and health functioning within the Whitehall II study. Occup Environ Med 59:777-784

Kuper H, Marmot M, Kuper H, Marmot M (2003) Job strain, job demands, decision latitude, and risk of coronary heart disease within the Whitehall II study. J Epidemiol Commun Health 57:147-153

Kuper H, Adami HO, Theorell T, Weiderpass E (2006) Psychosocial determinants of coronary heart disease in middle-aged women: a prospective study in Sweden. Am J Epidemiol 164:349-357

Lee S, Colditz G, Berkman L, Kawachi I (2002) A prospective study of job strain and coronary heart disease in US women. Int $\mathbf{J}$ Epidemiol 31:1147-1153 
Lynch J, Krause N, Kaplan GA, Tuomilehto J, Salonen JT (1997) Workplace conditions, socioeconomic status, and the risk of mortality and acute myocardial infarction: the Kuopio ischemic heart disease risk factor study. Am J Public Health 87:617-622

Markovitz JH, Matthews KA, Whooley M, Lewis CE, Greenlund KJ (2004) Increases in job strain are associated with incident hypertension in the CARDIA study. Ann Behav Med 28:4-9

Matthews KA, Gump BB (2002) Chronic work stress and marital dissolution increase risk of posttrial mortality in men from the multiple risk factor intervention trial. Arch Intern Med 162:309-315

Mosterd A, Hoes AW, Grobbee DE (1998) Epidemiology of heart failure: contours of an impending epidemic? Neth J Med 53:235-244

Netterstrøm B, Juel K (1988) Impact of work-related and psychosocial factors on the development of ischemic heart disease among urban bus drivers in Denmark. Scand J Work Environ Health 14:231-238

Netterstrøm B, Kristensen TS (2005) Psykisk arbejdbelastning og iskaemik hjertesygdom. Ugeskr Laeger 167(46):4348-4355

Netterstrøm B, Kristensen TS, Sjøl A (2006) Psychological job demands increase the risk of ischaemic heart disease: a 14-year cohort study of employed Danish men. Eur J Cardiovasc Prev Rehabil 13:414-420

O'Connell JB (2000) The economic burden of heart failure. Clin Cardiol 23:III6-III10

Orth-Gomer K, Wamala SP, Horsten M, Schenck-Gustafsson K, Schneiderman N, Mittleman MA (2000) Marital stress worsens prognosis in women with coronary heart disease: The Stockholm female coronary risk study. JAMA 284:3008-3014

Orth-Gomer K, Albus C, Bages N, DeBacker G, Deter HC, HermannLingen C, Oldenburg B, Sans S, Williams RB, Schneiderman N (2005) Psychosocial considerations in the European guidelines for prevention of cardiovascular diseases in clinical practice: Third Joint Task Force. Int J Behav Med 12:132-141

Raymond I, Pedersen F, Steensgaard-Hansen F, Green A, BuschSorensen M, Tuxen C, Appel J, Jacobsen J, Atar D, Hildebrandt P (2003) Prevalence of impaired left ventricular systolic function and heart failure in a middle aged and elderly urban population segment of Copenhagen. Heart 89:1422-1429

Roger VL, Weston SA, Redfield MM, Hellermann-Homan JP, Killian J, Yawn BP, Jacobsen SJ (2004) Trends in heart failure incidence and survival in a community-based population. JAMA 292:344350

Scottish Intercollegiate Guidelines Network, SIGN 50 (2008) A guideline developer's handbook revised edition. SIGN, Edinburgh

Siegrist J (1996a) Soziale Krisen und Gesundheit (Social crises and health). Hogrefe Verlag für Psychologie, Göttingen

Siegrist J (1996b) Adverse health effects of high effort-low reward conditions. J Occup Health Psychol 1:27-41
Siegrist J, Peter R, Junge A, Cremer P, Seidel D (1990) Low status control, high effort at work and ischemic heart disease: prospective evidence from blue-collar men. Soc Sci Med 31:1127-1134

Siegrist J, Strake D, Chandola T, Godin I, Marmot M, Niedhammer I, Peter R (2004) The measurement of effort-reward imbalance at work: European comparisons. Soc Sci Med 58:1483-1499

Steptoe A, Hamer M, Chida Y (2007) The effects of acute psychological stress on circulating inflammatory factors in humans: a review and meta-analysis. Brain Behav Immun 21:901-912

Stewart S, MacIntyre K, Capewell S, McMurray JJ (2003) Heart failure and the aging population: an increasing burden in the $21 \mathrm{st}$ century? Heart 89:49-53

Suadicani P, Hein HO, Gyntelberg F (1993) Are social inequalities as associated with the risk of ischaemic heart disease a result of psychosocial working conditions? Atherosclerosis 101:165-175

Theorell T, Floderus-Myrhed B (1977) 'Workload' and risk of myocardial infarction - a prospective psychosocial analysis. Int J Epidemiol 6:17-21

Tsutsumi A, Kayaba K, Hirokawa K, Ishikawa S (2006) Psychosocial job characteristics and risk of mortality in a Japanese community-based working population: the Jichi Medical School Cohort Study. Soc Sci Med 63:1276-1288

Tsutsumi A, Kayaba K, Kario K, Ishikawa S (2009) Prospective study on occupational stress and risk of stroke. Arch Intern Med 169:56-61

Tu ST, Wang IW, Lin HF, Liao YC, Lin RT, Liu CS, Hank Juo SH (2010) Carotid intima-media thickness and stiffness are independent risk factors for atherosclerotic diseases. J Investig Med 58:786-790

Uchiyama S, Kurasawa T, Sekizawa T, Nakatsuka H (2005) Job strain and risk of cardiovascular events in treated hypertensive Japanese workers: hypertension follow-up group study. J Occup Health 47:102-111

Utsugi M, Saijo Y, Yoshioka E, Sato T, Horikawa N, Gong Y, Kishi R (2009) Relationship between two alternative occupational stress models and arterial stiffness: a cross-sectional study among Japanese workers. Int Arch Occup Environ Health $82: 175-183$

Vahtera J, Kivimäki M, Pentti J, Linna A, Virtanen M, Virtanen P, Ferrie JE (2004) Organisational downsizing, sickness absence, and mortality: 10-town prospective cohort study. BMJ 6 328(7439):555-560

Virtanen M, Ferrie JE, Singh-Manoux A, Shipley MJ, Vahtera J, Marmot MG, Kivimäki M (2010) Overtime work and incident coronary heart disease: the Whitehall II prospective cohort study. Eur Heart J 31:1737-1744 